\title{
Influência do controle vetorial sobre a redução da população de mosquitos
}

\author{
Mendes, G. A. ${ }^{1}$; Tomé, T. ${ }^{2}$; Souza, D. R. ${ }^{1}$; Pinheiro, C. J. G. ${ }^{1}$ \\ 1 Departamento de Química e Física, Centro de Ciências Agrárias, Universidade Federal do Espírito Santo, Alegre, ES, \\ Brasil. \\ 2 Departamento de Física Geral, Instituto de Física da Universidade de São Paulo, São Paulo, SP, Brasil.
}

\begin{abstract}
Resumo
Neste trabalho investigamos como o controle de natalidade, realizado pela redução de criadouros de mosquitos, contribui para a redução populacional de mosquitos. Para isso usamos um modelo de gás na rede em que cada sítio representa um mosquito(fêmea). O processo de reprodução é catalítico e o processo de mortalidade é espontâneo. A redução de criadouros é modelada como uma anisotropia na rede, que impossibilita a reprodução de mosquitos em determinados sítios.
\end{abstract}

Keywords (Palavras chaves): modelos epidêmicos, processo de contato, dengue.

\section{Introdução}

Neste trabalho apresentamos um modelo estocástico espacialmente estruturado, baseado no modelo de contato proposto por Harris [1-6] para descrever o processo de espalhamento de mosquitos em um ambiente heterogêneo. Para mimetizar as condições ambientais, usamos uma rede regular com anisotropia, em que a anistropia representa a ausência de criadouros. Como somente as fêmeas são hematófagos e assim responsáveis pela transmissão de vírus como a dengue para os humanos, não consideramos explicitamente a população de mosquitos machos e a fase larval, dando ênfase à fase adulta e os processos de reprodução e morte.

\section{Metodologia}

Para mimetizar um ambiente com condições heterogêneas em que alguns espaços são desfavoráveis à reprodução, e os processos de nascimento e morte são eventos estocásticos, consideramos uma rede regular bidimensional com anisotropia. A cada sítio da rede associamos uma variável estocástica $\eta_{i j}$ que denota a ocupação do sítio por uma fêmea adulta. Os estados permitidos para a variável estocástica: são: $\left(\eta_{i j}=0\right),\left(\eta_{i j}=1\right)$ ou $\left(\eta_{i j}=2\right)$, que denotam um sítio vazio, ocupado ou inacessível, respectivamente. O processo de reprodução ocorre com probabilidade $p_{r}=n_{1} \lambda \zeta(1+\lambda)$, em que $n_{1}$ é o número de primeiros vizinhos ocupados, $\zeta$ é a coordenação da rede, e $\lambda$ é a taxa de reprodução. $O$ processo de morte ocorre com probabilidade $\mathrm{p}_{\mathrm{m}}=1 /(1+\lambda)$.

Nas simulações computacionais, a rede é inicializada com uma densidade $r$ de sítios inacessíveis e o sítio central é ocupado. A cada instante sorteia-se um sítio e um número aleatório $\omega(0 \leq \omega<1)$. Se $\eta_{i j}=0$ e $\omega \leq p_{r}$, o sítio é ocupado. Se $\eta_{i j}=1$ e $\omega \leq p_{m}$, o sítio torna-se vazio. Esta dinâmica prossegue até que o estado estacionário seja atingido. Por meio de simulações computacionais do modelo analisamos a dependência entre o limiar de reprodução e o controle de criadouros r.

\section{Resultados e discussão}

A figura 1 exibe a densidade estacionária de fêmeas $\rho$ versus a taxa de reprodução $\lambda$. Para valores de $\lambda<\lambda_{c}$ a densidade tende a zero no limite termodinâmico. Acima de $\lambda_{c}$ a densidade tende a um valor não nulo. 


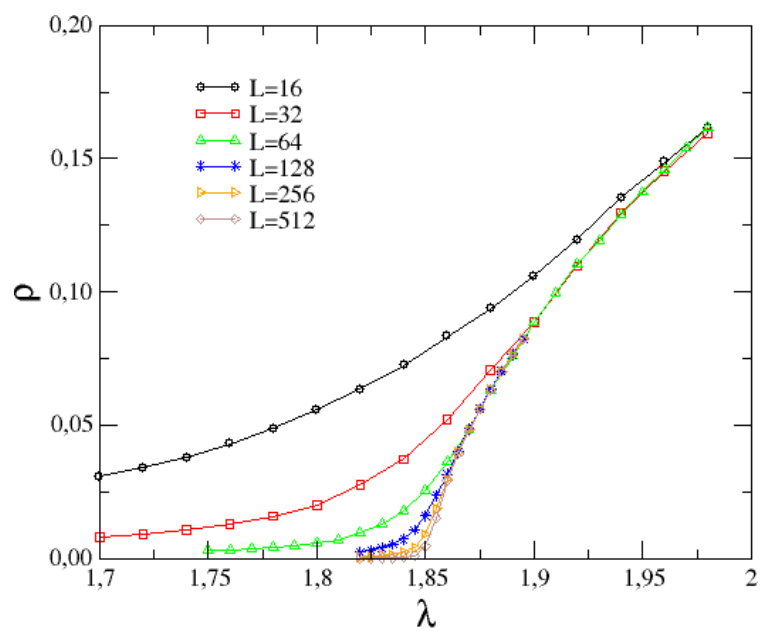

Figura 1: Densidade estacionária vs taxa de infecção $\lambda$, para diferentes tamanhos de rede, com $r=0,10$.

Para determinar o ponto crítico desta transição de fase calculamos o ponto de inflexão de cada curva de densidade referente a um tamanho de rede $e$ extrapolamos para o limite de tamanho infinito. $\mathrm{Na}$ figura 2, acima da linha crítica (fase ativa) ocorre o crescimento da população de mosquitos; e abaixo da linha crítica a densidade de mosquitos se anula no limite termodinâmico. Verifica-se que reduzindo os criadouros (área propícia a reprodução) há uma expansão da fase inativa.

\section{Conclusões}

Por meio de simulações estacionárias calculamos os limiares de reprodução em função da redução de criadouros. A partir dos resultados obtidos, verifica-se que o limiar de reprodução cresce a medida que se reduz as áreas proprícias à reprodução, evidenciando a importância de reduzir a quantidade de criadouros para evitar a proliferação de mosquitos transmissores de doenças.

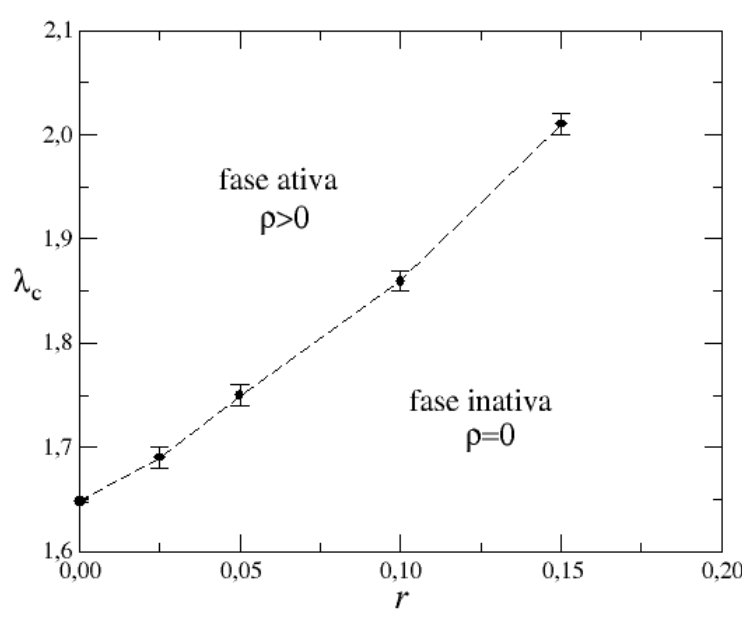

Figura 2: Diagrama de fase do modelo. A linha tracejada é um guia para os olhos.

\section{Agradecimentos}

Os autores agradecem ao Fundo de Apoio a Ciência e Tecnologia da Prefeitura de Vitória-ES pelo apoio financeiro.

\section{Referências}

[1] PAIXÃO, C. A.; CHARRET, I. C.; LIMA, R. R. Braz. Jour. Phys., v. 42, 132-136, 2012.

[2] SOUZA, D. R.; TOMÉ, T.; PINHO, S. T. R.; BARRETO, F. R.; OLIVEIRA, M. J. Phys. Rev. E 87, 012709, 2013.

[3] NEWTON, E. A.; REITER, P. Am. J. Trop. Med. Hyg. 47, 709, 1992.

[4] KEELING, M. J. Proc. R. Soc. London B 266, 859, 1999.

[5] HARRIS, T. E. Ann. Probab., 2, 969, 1974.

[6] TOMÉ, T., OLIVEIRA, M. J. Dinâmica Estocástica e Irreversibilidade. Edusp, São Paulo, 2001. 